\title{
A utilização das metodologias ativas como ferramenta de inclusão dos alunos com deficiência auditiva em sala de aula: desafios e oportunidades
}

As metodologias ativas surgem como uma alternativa na busca de auxiliar a aprendizagem de estudantes com diferentes interesses e habilidades, servindo de ferramenta para o educador atrair e manter a atenção dos alunos, motivando-os a buscar conhecimento e serem protagonista do seu próprio aprendizado. 0 objetivo deste estudo é mensurar os desafios e oportunidades da inserção dessas metodologias para alunos com deficiência auditiva. Espera-se fornecer um material de suporte ao professor, que lhe permita vincular o conteúdo da aula com as diferentes metodologias ativas, através de estudos já realizados, permitindo por meio deste artigo colaborar com a aquisição do saber do aluno, bem como contribuir para seu desenvolvimento educativo.

\section{The use of active methodologies as a tool for the inclusion of students with hearing impairment in the classroom: challenges and opportunities}

\begin{abstract}
Active methodologies emerge as an alternative in the quest to assist the learning of students with different interests and skills, serving as a tool for the educato to attract and maintain students' attention, motivating them to seek knowledge and be protagonists of their own learning. The objective of this study is to measure the challenges and opportunities of inserting these methodologies for students with hearing impairment. It is expected to provide support material to the teacher, which allows him to link the content of the class with the different active methodologies, through studies already carried out, allowing through this article to collaborate with the acquisition of the student's knowledge, as well as contribute to his learning. educational development.
\end{abstract}

Keywords: Inclusion; Deafness; Protagonist; Learning.

Topic: Práticas, Didática e Metodologias do Ensino

Reviewed anonymously in the process of blind peer.
Received: 20/10/2019

Approved: 02/02/2020
Marieli Rosseto (D)

Universidade de Passo Fundo, Brasil http://lattes.cnpq.br/8172882358532158 http://orcid.org/0000-0003-4741-2224

mmarielirossetto@gmail.com

Valeska Morgana Corrêa Batistella

Universidade do Estado de Mato Grosso, Brasil

http://lattes.cnpq.br/0459504099701173

valeska_morgana@hotmail.com

Lillian Avila Massuda (10

Universidade de Passo Fundo, Brasi

http://lattes.cnpq.br/4944423715074396

http://orcid.org/0000-0001-5039-9011

lillianavilamassuda@gmail.com

\author{
Bruna Elisangela Pessini Ostwald \\ Universidade de Passo Fundo, Brasil \\ http://orcid.org/0000-0003-2681-4582 \\ bruna.elisangela@hotmail.com \\ Roberth Sturmer \\ Universidade de Passo Fundo, Brasil \\ roberthsturmer@hotmail.com \\ Suelen Marques \\ Universidade de Passo Fundo, Brasil \\ http://lattes.cnpq.br/6400649230689111 \\ http://orcid.org/0000-0003-2196-9083 \\ suelenmarques1992@gmail.com
}

Referencing this:

ROSSETO, M.; BATISTELLA, V. M. C.; MASSUDA, L. A.; OSTWALD, B. E. P.; STURMER, R.; MARQUES, S.. A utilização das metodologias ativas como ferramenta de inclusão dos alunos com deficiência auditiva em sala de aula: desafios e oportunidades. Educationis, v.8, n.1, p.53-60, 2020. DOI: http://doi.org/10.6008/CBPC2318-3047.2020.001.0005 


\section{INTRODUÇÃO}

A Inclusão escolar vem de encontro a ideia que todas as pessoas devem ter acesso igualitário ao sistema de ensino. $O$ foco está principalmente nas crianças e jovens que apresentam algum tipo de limitação, como por exemplo a surdez. A audição é um dos cinco sentidos que possuem extrema importância na comunicação. A surdez, por sua vez, deve ser bastante discutida, visto que a deficiência não deve limitar os direitos de qualquer indivíduo (MACHADO et al., 2019).

A perda auditiva (ou seja, perda auditiva superior a $40 \mathrm{~dB}$ ) afeta a vida de $5,3 \%$ da população mundial - 360 milhões de pessoas (Organização Mundial da Saúde). No Brasil, são aproximadamente 10 milhões de pessoas surdas. Isso equivale a 5\% da população brasileira (IBGE, 2010). A inclusão do aluno surdo na escola regular é complexa, mas é caracterizada como uma forma de inclusão social, visto que eles têm uma linguagem própria, que é a língua de sinais.

Entretanto não deve se limitar a isto, as tecnologias podem ser uma ferramenta de comunicação aluno/professor, onde os educadores podem conduzir o desenvolvimento do aluno através de ações educativas que contemplem o envolvimento dos alunos com as tecnologias disponíveis, oportunizando seu desenvolvimento e socialização. As metodologias ativas vêm de encontro a isso, oportunizando ao aluno ser protagonista de seu próprio aprendizado através do incentivo oferecido pela comunidade acadêmica, que desenvolve a sua capacidade em absorver conteúdos de maneira autônoma.

O estudo foi desenvolvido através de pesquisa bibliográfica, onde se analisou os desafios e oportunidade do uso das metodologias ativas para educação de alunos surdos, visando contribuir para seu desenvolvimento e inclusão na sociedade. Para tal refletiu-se sobre as condições do aluno com surdez, elencar os tipos de metodologias ativas através de revisão de literatura, vincular o uso das metodologias ativas com o aprendizado do aluno com surdez, apresentar como as metodologias ativas contribuem no processo de aprendizagem e de socialização do indivíduo.

Os surdos apresentam alguns dos problemas desafiantes para a educação especial, a ausência da audição, o que interfere na recepção e produção da linguagem, e consequentemente em todas as áreas de seu desenvolvimento (BELTRAMI et al., 2015). Lang (1993, citado por SANTANA et al., 2017) apresentam a importância de cientistas surdos e suas contribuições para a humanidade, elencando que as limitações de cada um não foram fatores limitantes para a aquisição de conhecimento em prol da pesquisa em diferentes áreas para benefício da sociedade, como apresentado no Quadro 1.

O processo educacional das pessoas surdas tem sido continuamente marcado por decisões políticas que envolvem juízos de valor sobre a condição humana e configura-se de diferentes maneiras no decorrer da história (BASSO, 2003).

Pesquisas desenvolvidas no Brasil e no exterior indicam que um número significativo de sujeitos Surdos que passaram por vários anos de escolarização apresenta competência para aspectos acadêmicos muito aquém do desempenho de alunos ouvintes, apesar de suas capacidades cognitivas iniciais serem semelhantes (LACERDA, 2009). 
Quadro 1: Cientistas surdos.

\begin{tabular}{|l|l|}
\hline $\begin{array}{c}\text { CIENTISTA COM } \\
\text { DEFICIÊNCIA } \\
\text { AUDITIVA }\end{array}$ & \multicolumn{1}{c|}{ CONTRIBUIÇÃo PARA A CIÊNCIA } \\
\hline Guillaume Amontons & $\begin{array}{l}\text { Físico, surdo profundo e realizava pesquisas experimentais envolvendo temperatura. Pioneiro na } \\
\text { compreensão de temperatura absoluta. }\end{array}$ \\
\hline John Goodricke & $\begin{array}{l}\text { Astrônomo surdo profundo que pesquisou e lançou as bases para os estudos das estrelas binárias. Na } \\
\text { constelação de Perseu, há uma estrela chamada Algol, também conhecida como a 'estrela do demônio', } \\
\text { cujas misteriosas variações de brilho foram investigadas por John Goodricke. }\end{array}$ \\
\hline Annie Jump Cannon & $\begin{array}{l}\text { A cratera Cannon foi assim nomeada em homenagem a Annie Jump Cannon, astrônoma que se tornou } \\
\text { surda e contribuiu para o desenvolvimento da classificação estelar contemporânea. }\end{array}$ \\
\hline Leo lesquereux & $\begin{array}{l}\text { Americano reconhecido como o fundador norte americano da paleobotânica, que visa investigar as } \\
\text { plantas no registro fóssil. }\end{array}$ \\
\hline Frederick Barnard & $\begin{array}{l}\text { Pesquisador da educação, foi um dos primeiros presidentes da associação americana para o progresso } \\
\text { da Ciência no século XIX. Ele era surdo e publicou diversos trabalhos sobre a educação de surdos. }\end{array}$ \\
\hline Thomas Meehan & $\begin{array}{l}\text { Auxiliou Charles Darwin a desenvolver sua teoria da evolução. Ficou conhecido como o 'pai americana } \\
\text { da horticultura', sendo está um ramo da ciência que visa investigar técnicas para a produção econômica } \\
\text { de plantas. }\end{array}$ \\
\hline Harry Lang & $\begin{array}{l}\text { Físico, mestre em Engenharia Elétrica e doutor de ensino de ciências pela University of Rochester. Harry } \\
\text { Lang contribuiu grandemente para o avanço das pesquisas na área de ensino de ciências para surdos, } \\
\text { apresentando diversas publicações de impacto na área. }\end{array}$ \\
\hline
\end{tabular}

Fonte: Lang (1993, citado por SANTANA et al., 2017).

A educação de surdos vem sendo debatida e enfrentando grandes desafios, onde uns defendem uma educação oralista e outros a língua de sinais, mas ambos concordam que eles devem receber uma instrução adequada para exercerem sua cidadania (CRUZ et al., 2018). Contudo, a Língua Brasileira de Sinais (Libras) foi decretada a segunda língua oficial no Brasil, através do Decreto 5.626 em 2005.

Porém somente o uso da língua de sinais não é suficiente em sala de aula. E o uso de materiais didáticos mais comuns nas instituições e utilizados por educadores são os livros concretos; em português e pouco acessível para estudantes surdos (CRUZ et al., 2018). E com um mundo cada vez mais conectado, onde as mídias têm desempenhado um papel de destaque na sociedade, influenciando nos modos de ser, pensar e agir (CUNHA et al., 2015).

O desafio é como inserir na escola um sistema comunicativo que contemple ao mesmo tempo: experiências culturais heterogêneas, o entorno das novas tecnologias da informação e da comunicação, além de configurar o espaço educacional como um lugar onde o processo de aprendizagem conserve seu encanto (MORAN, 2007).

As pessoas com deficiência auditiva enfrentam diversos obstáculos, geralmente impostos pela sociedade, que os julgam incapazes, por possuírem dificuldade de participar da educação escolar regular. Essa dificuldade poderia ser minimizada ao oferecer estímulos adequados ao seu potencial cognitivo, sócio afetivo, linguístico e político-cultural.

As novas tecnologias introduziram nas salas de aula um aparato tecnológico que aparenta dar um ar de modernidade, mas seja ao aroma do álcool do material saído dos mimeógrafos ou da projeção com movimento e cores dos datashows, o âmago do processo não foi minimamente tocado: a efetividade da aprendizagem (MACHADO et al., 2017). Uma ferramenta que vem de encontro a esse objetivo são as metodologias ativas, estas permitem que o aluno conheça além de sua realidade e tenha uma visão ampla da sociedade, uma vez que o cenário da educação vem sofrendo grandes transformações nas últimas décadas. 


\section{METODOLOGIA}

Metodologias ativas são estratégias de ensino que objetivam a participação efetiva dos estudantes na construção do processo de aprendizagem, de forma flexível, interligada e hibrida (BACICH et al., 2018). Enquanto a escola tradicional, é padronizada, avaliando e ensinando todos de forma igual, independentemente de suas e exige resultados previsíveis, ignora que a sociedade do conhecimento é baseada em competências cognitivas, pessoais e sociais (SOUZA et al., 2015). As metodologias ativas têm concepções diferentes, baseada na educação crítico-reflexiva com base em estímulo no processo ensinoaprendizagem, resultando em envolvimento por parte do educando na busca pelo conhecimento (MACEDO et al., 2018). A Figura 1 retrata as principais diferenças entre as metodologias tradicionais e ativas.

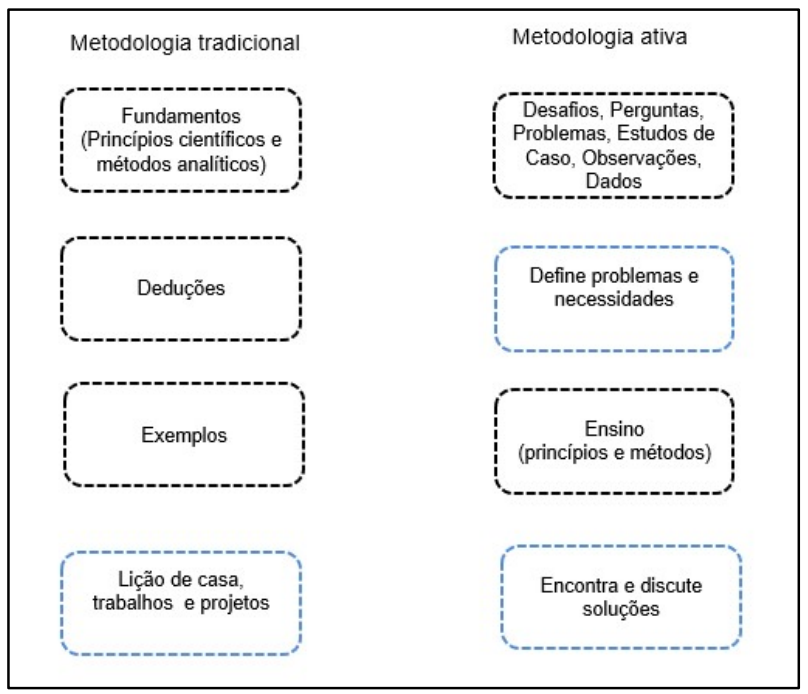

Figura 1: Metodologias tradicionais versus metodologia ativa. Fonte: Adaptado de Macedo et al. (2018).

As metodologias ativas estão cada vez mais presentes nas salas de aulas, muitas vezes em atividades aleatórias, mas também há escolas que se dedicam a ensinar dessa forma. No Brasil, pode-se elencar a Escola Municipal Amorim Lima, localizada no estado de São Paulo, que possui um projeto político pedagógico inspirado na Escola da Ponte, de Portugal. Onde cada aluno possui um tutor, encontrando-se semanalmente pelo período de cinco horas, nesse momento recebe apostilas com roteiros de pesquisa e objetivos que devem alcançados até a próxima semana, o trabalho é realizado em equipe e os professores orientam de acordo com a necessidade. Em Foz do Iguaçu, tem a Uniamérica que utiliza metodologias ativas, dentre elas ensino por projetos, aula invertida. $\mathrm{O}$ aluno tem autonomia para escolher um problema real da sociedade para trabalhar, estudando os conteúdos antes das aulas, e utilizando o tempo em classe para esclarecer dúvidas com os professores, o conteúdo é disponibilizado online e realizam encontros para debater os projetos.

As metodologias ativas já são discutidas no meio acadêmico a algum tempo, mesmo que com nomenclaturas diferentes. Estudos de Dewey (1959) convergem com as ideias de Freire (1996), em que as experiências de aprendizagem devem despertar a curiosidade do aluno, e permitir que ao pensar o concreto, conscientize-se da realidade, questionando-a e fazendo com que a construção do conhecimento seja transformadora (SILVA, 2018). 


\section{DISCUSSÃO TEÓRICA}

Em um mundo conectado e digital, as metodologias ativas expressam-se por modelos de ensino híbridos, exercendo diversas combinações que resultam em atividades diferenciadas que contribuem na aprendizagem do aluno (BACICH et al., 2018). Há vários tipos de metodologias ativas que podem ser aplicadas em sala de aula dependendo do tipo de atividade e o objetivo que o professor busca alcançar, como demostrado no Quadro 2.

Quadro 2: Exemplos de metodologias ativas e objetivo.

\begin{tabular}{|l|l|}
\hline \multicolumn{1}{|c|}{ METODOLOGIA } & \multicolumn{1}{c|}{ OBJETIVO } \\
\hline Seminários & $\begin{array}{l}\text { Expor ideias para uma ou mais pessoas. É o espaço onde um grupo debate temas ou problemas que } \\
\text { são colocados em discussão previamente. }\end{array}$ \\
\hline Estudo Dirigido & Estudar sob a orientação e diretividade do professor, visando minimizar dificuldades específicas. \\
\hline Júri simulado & $\begin{array}{l}\text { Simular um júri a partir de um problema. A partir disso são apresentados argumentos de defesa e de } \\
\text { acusação, levando ao grupo a realizar uma análise e avaliar um fato proposto com objetividade e } \\
\text { realismo. }\end{array}$ \\
\hline Estudo de caso & $\begin{array}{l}\text { Utiliza casos reais ou fictícios, envolvendo os estudantes com o objetivo de encontrar a melhor } \\
\text { solução para o problema. }\end{array}$ \\
\hline Sala de aula invertida & $\begin{array}{l}\text { Propõe ao aluno ter autonomia e poder estudar e acessar a informação onde e quando quiser, por } \\
\text { meio dos materiais que o professor disponibiliza e durante a aula, as discussões são focadas nas } \\
\text { dificuldades que os alunos encontraram. }\end{array}$ \\
\hline $\begin{array}{l}\text { Aprendizagem baseada } \\
\text { em problemas }\end{array}$ & $\begin{array}{l}\text { É um método transdisciplinar onde os estudantes aprendem a solucionar problemas reais ou } \\
\text { simulados a partir de um contexto real. O ensino é centrado no aluno, que assume o protagonismo } \\
\text { de seu próprio aprendizado por meio da pesquisa. }\end{array}$ \\
\hline Gamificação & $\begin{array}{l}\text { Usar a mecânica, estética e pensamento dos jogos para envolver as pessoas, motivar ações, } \\
\text { promover a aprendizagem e resolver problemas. }\end{array}$ \\
\hline Ensino hibrido & Mistura ferramentas online e off-line objetivando compreender a melhor forma do aluno aprender. \\
\hline $\begin{array}{l}\text { Aprendizagem entre } \\
\text { pares ou grupos }\end{array}$ & $\begin{array}{l}\text { Promove a interação entre os alunos, que estudam juntos. Porém primeiramente as atividades são } \\
\text { realizadas de forma individual e após revisão do professor, há a discussão com um par para posterior } \\
\text { explanagem em sala de aula. }\end{array}$ \\
\hline $\begin{array}{l}\text { Aprendizagem baseada } \\
\text { em projetos }\end{array}$ & $\begin{array}{l}\text { Os alunos se envolvem com tarefas e desafios para resolver um problema ou desenvolver um projeto } \\
\text { que também tenha ligação com sua vida fora da sala de aula. }\end{array}$ \\
\hline
\end{tabular}

Fonte: Anastasiou et al. (2004); Kapp (2012); Souza (2015); Moran (2018).

Qualquer metodologia acima mencionada pode ser adaptada para tornar a aula mais atrativa para alunos com surdez, desde que seja respeitado as limitações de cada um. Observa-se, no entanto, que em muitos casos os estudantes apenas se fazem presentes na sala de aula e não tem garantido os direitos previstos em lei, devido a carência de material adaptado aliado a outros fatores como formação do professor e falta de adaptação curricular acabam por dificultar a aprendizagem de alunos com algum tipo de deficiência (PEROVANO et al., 2019).

Vários estudos relatam como essas metodologias podem ser aplicadas nas diferentes, de modo que contemple as necessidades de ensino do aluno com surdez, que pode desfrutar de uma aula mais interativa e de maior aprendizado. Porém estas metodologias podem ser adaptadas dependendo do conteúdo a ser trabalhado, e muito ainda se tem a desenvolver.

Corrêa et al. (2017) investigaram as possibilidades de trabalhar os conteúdos da matemática com alunos surdos, utilizando diferentes recursos. A pesquisa foi qualitativa e aplicada a três alunos, através do uso das ferramentas: geoplano e geoespaço como materiais concretos, um quebra-cabeça como jogo e os softwares educacionais SuperLogo. Eles concluem que o uso do computador foi o mais motivador, que obteve maior sucesso. E atribuem esse sucesso ao fato dos alunos estarem em contato com a tecnologia, 
onde o computador traz recursos que garantem a esses alunos a possibilidade de produzir matemática.

Dias et al. (2017) desenvolveram um estudo objetivando discutir acerca do processo de ensinoaprendizagem da língua espanhola para alunos surdos, avaliando se a surdez é um obstáculo nesse processo e se as práticas de letramento que envolvem esses alunos condizem com a conduta e identidade surdas. A pesquisa foi realizada por meio de observação de aulas de espanhol no ensino médio em cinco alunos surdos, onde foi proposto pelos autores o uso de imagens como metodologia, e perceberam que o uso da imagem foi fundamental para o ensino-aprendizagem e letramento dos alunos com surdez. Nesta atividade aplicada sem o uso desse recurso, foi perceptível que os alunos não entenderam a proposta ou tiveram entendimento comprometido.

Dias et al. (2016) também estudaram o uso de imagens como prática de letramento de alunos surdos. E concluíram que esta estratégia além de facilitar a aprendizagem desses alunos, também lhes proporciona melhor entendimento do mundo que os cerca. Rodrigues (2018) estudou sobre a utilização do aplicativo Hand Talk para surdos, como ferramenta de melhoria da acessibilidade na educação, e evidenciou que com o emprego da tecnologia, propiciou aos alunos a aprendizagem de uma segunda língua e consequente participação ativa dos mesmos nesse processo de consolidação do ensino.

Tavares et al. (2018) elaboraram um percurso investigativo com o objetivo de construir uma Unidade de Ensino Potencialmente Significativa (UEPS) para o ensino de Citologia para estudantes surdos do $1^{\circ}$ ano do ensino médio e elegeram a Teoria da Aprendizagem Significativa de Ausubel como aporte teórico e a pesquisa-ação

Lima Junior et al. (2019) realizaram uma pesquisa bibliográfica, objetivando argumentar e debater sobre a inclusão e a realidade dos níveis e modalidades da educação escolar, visando refletir sobre a inclusão dos surdos na universidade. E concluem que é preciso avaliar vários aspectos antes do ingresso do aluno surdo no ensino superior, como: analisar sua trajetória escolar e o contexto institucional em que ele busca se inserir. Pois a universidade é algo novo para esses alunos, que estavam habituados com a educação especial, visto que há regras que precisam ser cumpridas e a comunicação oral-auditiva é fundamental no ensino-aprendizagem e de socialização. E muitas vezes o professor não está preparado, por não conhecer a língua de sinais, e acaba compartilhando de ideias de forma geral ignorando a dificuldade de se relacionar que o aluno apresenta.

É importante que o professor busque conhecer a surdez e seu aluno surdo, como ele se comporta, suas características e peculiaridades. Se o professor possui um aluno surdo, ele deve saber pelo menos o básico da Libras (CORRÊA et al., 2017). Esse preparo do professor deve existir independentemente do nível de ensino e/ou disciplina a ser cursada, só assim será possível existir inclusão.

Os cursos das áreas de licenciaturas vêm buscando dinamizar com as turmas e faze-as ter algum tipo de vivência junto aos variados tipos de alunos que podem encontrar no decorrer da sua profissão, e as metodologias ativas também podem ser uteis nesse sentido. Leão et al. (2019) estudaram o ensino de libras em um curso de Pedagogia por meio da aprendizagem baseada em problemas, onde durante o $8^{\circ}$ semestre do curso, onde os grupos foram instruídos a resolver o problema, e a partir deste surgiram várias opiniões 
divergentes que permitiu um debate interessante sobre a temática.

Aulas assim fazem o discente ter uma visão ampla de uma situação, e quando o mesmo chegar na sala de aula e encontrar situações similares, vai ter mais facilidade de conduzir a aula, uma vez que já teve contato com a situação, mesmo que teoricamente.

\section{CONCLUSÕES}

Os alunos com surdez apresentam algumas limitações que podem ser superadas com o uso de metodologias ativas pelo professor, desde que o profissional esteja apto a fazer essa vinculação. Pois além de conhecer as especificidades do aluno com surdez, deve estar ciente de suas limitações antes de propor uma atividade diferente.

As metodologias ativas são vistas como ferramentas para despertar o interesse dos alunos em sala de aula, tornando-os protagonistas de sua própria aprendizagem. Visto que os alunos se sentem entusiasmados em aprender quando proposto de formas diferentes, que vinculam tecnologias e atividades que vão além da sala de aula. Onde eles possam usufruir de suas habilidades individuais em prol do desenvolvimento das tarefas propostas.

\section{REFERÊNCIAS}

BACICH, L.; MORAN, J.. Metodologias ativas para uma educação inovadora: uma abordagem teórico-prática. Porto Alegre: Penso, 2018.

BASSO, I. M. S.. Mídia e educação de surdos: transformações reais ou uma nova utopia?. Ponto de Vista: Revista de Educação e Processos Inclusivos, n.5, p.113-128, 2003.

BELTRAMI, C. M.; MOURA, M. C.. A educação do surdo no processo de inclusão no Brasil nos últimos 50 anos (19612011). Revista Eletrônica de Biologia, v.8, n.1, p.146-161, 2015.

BRASIL. Decreto no 5.626, de 22 de dezembro de 2005. Regulamenta a Lei no 10.436, de 24 de abril de 2002, que dispõe sobre a Língua Brasileira de Sinais - Libras, e o art. 18 da Lei no 10.098, de 19 de dezembro de 2000. Brasília: DOU, 2005.

CORRÊA, W. C. R.; SOUZA, L. O.. O ensino de matemática para surdos: uma análise sobre o uso de materiais concretos, jogos e softwares matemáticos. In: ENCONTRO GOIANO DE EDUCAÇÃO MATEMÁTICA, 6. Anais. 2017. p.288-299.

CRUZ, J.; CRUZ, R.; CAMPELO, W.. A utilização de livros didáticos digitais em libras na educação dos surdos. Littera, v.9, 2018.

CUNHA, C. E. V.; FREITAS, L. A. A.; SCHAAN, L.; COIRO, M.; LORENZONI, N. V.; MACHADO, S.. Educomunicação e TIC nas escolas para professores. Porto Alegre: Secretaria da Educação do Estado do Rio Grande do Sul, 2015.

DIAS, M. S.; KODAMA, Q. P.. Ensino de língua espanhola para surdos: concepções e desafios diários. Comunicaciones en Humanidades, n.5, p.87-93, 2017.
DIAS, M. S.; PEIXOTO, W. R. S.. O uso de imagens como prática de letramento de alunos surdos. In: ENCONTRO INTERNACIONAL DE FORMAÇÃO DE PROFESSORES E FÓRUM PERMANENTE DE INOVAÇÃO EDUCACIONAL, 9. Anais. 2016.

KAPP, K.. The Gamification of Learning and Instruction: Game-based Methods and Strategies for Training and Education. Pfeiffer, 2012

LACERDA, C. B. F.. Uma escola, duas línguas: letramento em língua portuguesa e língua de sinais nas etapas iniciais de escolarização. Porto Alegre: Mediação, 2009.

LEÃO, M. F.; AGAPITO, F. M.. Ensino de Libras em um Curso de Pedagogia por meio da aprendizagem baseada em problemas. Revista Educação e Emancipação, v.12, n.1, p.186-203, 2019

LIMA JUNIOR, G. V.; VENCESLAU, K. M. C.; SILVA, N. D.. Estudos culturais, ensino e diversidades-surdos universitários: reflexão na universidade. Revista de Pesquisa Interdisciplinar, v.2, n.2, 2019

MACEDO, K. D. S.; BECK, C. L. C.; SILVA, K. K. D.. Active learning methodologies: possible paths to innovation in health teaching. Escola Anna Nery, v.22, n.3, p.1-9, 2018. DOI: http://dx.doi.org/10.1590/2177-9465-ean-2017-0435

MACHADO, A. B.; VOLPATO, A. N.; PELIPPE, D. B.; BERNINI, D. S. D.; FREIRE, D. M. M.; SALVE, G. B.; ANDRADE, I. C. F.; PORTAL, L. L. F.; CHAGA, M. M.; ARRUDA, M. P.; RIBEIRO, O. M.. DIAS, S. R.. Práticas inovadoras em metodologias ativas. Florianópolis: Contexto Digital, 2017. 
MACHADO, L. K. P.; SILVA, F. A. P.. Saúde e surdez: odontologia inclusiva. In: ENCONTRO DE EXTENSÃO, DOCÊNCIA E INICIAÇÃO CIENTÍFICA. Anais. 2019.

MORAN, J. M.. As mídias na educação: "Desafios na Comunicação Pessoal”. 3 ed. São Paulo: Paulinas, 2007.

MORAN, J.. Metodologias ativas para uma aprendizagem mais profunda. Metodologias ativas para uma educação inovadora: uma abordagem teórico-prática. Porto Alegre: Penso, 2018.

PEROVANO, L. P.; PONTARA, A. B.; MENDES, A. N. F.. Desenvolvimento de materiais didáticos para o ensino de química numa perspectiva inclusiva. In: SEMINÁRIO NACIONAL DE EDUCAÇÃO ESPECIAL E DO SEMINÁRIO CAPIXABA DE EDUCAÇÃO INCLUSIVA, 1. Anais. 2019. p.801807.
RODRIGUES, M.. A utilização do aplicativo Hand Talk para surdos, como ferramenta de melhora da acessibilidade na educação. CIET/EnPED, 2018.

SILVA, B. S.. Inovações na prática pedagógica: formação continuada de professores para competências de ensino no século XXI. Crescer em Rede, 2018.

SOUZA, C. A.; MORALES, O. A. T.. Mudando a educação com metodologias ativas. Coleção Mídias Contemporâneas. Convergências Midiáticas, Educação e Cidadania: aproximações jovens. UEPG, 2015.

SOUZA, S. C.. Aprendizagem Baseada em Problemas (ABP): Um Método Transdisciplinar de Aprendizagem para Ensino Educativo. 2015

TAVARES, E. B.; ANIC, C. C.; NETO, J. S. C.. Citologia para estudantes surdos: uma unidade de ensino potencialmente significativa. Revista de Estudos e Pesquisas sobre Ensino Tecnológico, v.4, n.8, 2018.

A CBPC - Companhia Brasileira de Produção Científica (CNPJ: 11.221.422/0001-03) detém os direitos materiais desta publicação. Os direitos referem-se à publicação do trabalho em qualquer parte do mundo, incluindo os direitos às renovações, expansões e disseminações da contribuição, bem como outros direitos subsidiários. Todos os trabalhos publicados eletronicamente poderão posteriormente ser publicados em coletâneas impressas sob coordenação da Sustenere Publishing, da Companhia Brasileira de Produção Científica e seus parceiros autorizados. Os (as) autores (as) preservam os direitos autorais, mas não têm permissão para a publicação da contribuição em outro meio, impresso ou digital, em português ou em tradução. 